\title{
Perspectives of primary healthcare providers on implementing cancer screening services in tribal block of Maharashtra, India
}

\author{
Anushree D. Patil, Neha R. Salvi', Begum Shahina ${ }^{2}$,A. Sharmila Pimple³ ,A. Gauravi Mishra ${ }^{3}$, L. Sanjay Chauhan, \\ Beena Nitin Joshi ${ }^{4}$
}

\begin{abstract}
Background: Breast, cervical, and oral cancers contribute to majority of cancer deaths among women in India. However, there is poor implementation of screening programs at primary health care (PHC). There is a need to understand the perspectives of healthcare providers at PHC level for feasibility of implementation of a cost-effective cancer screening program, particularly in the rural and tribal areas that are under served by cancer services. Materials and Methods: A continuous medical education (CME) program on "Prevention and early detection of common cancers" was held for all Medical Officers of Palghar District, Maharashtra. A self-administered questionnaire was used to assess the knowledge, attitude, practices, perspectives regarding common cancers, screening methods, and human papilloma virus (HPV) vaccination.A pre- and post-assessment was carried out before the commencement and on completion of the CME among 76 participants. Results: Knowledge about etiology of common cancers was high; however, awareness of risk factors was low. There were knowledge gaps about HPV vaccination. There was overall improvement about the available screening methods and knowledge of HPV vaccine and dosages after the CME (pretest $65 \%$ to posttest $95 \%$ ). Providers had no experience in performing cervical cancer screening on a routine basis. While the majority of the providers (97\%) indicated that screening for cancer was essential and feasible at PHC level; however, training (52\%) and resources $(53 \%)$ would be needed. Conclusion: Healthcare providers though from the underserved tribal areas, were optimistic to implement screening for common cancers and were willing to take training for the same. This emphasizes the need for educating and training the healthcare providers with simple techniques for effective implementation of cancer screening programs in underserved areas.
\end{abstract}

Key words: Cervical cancer screening, healthcare providers, India, primary health care, tribal

\section{Introduction}

The continuing global demographic and epidemiologic transitions signal an ever-increasing cancer burden over the next decades, particularly in low- and middle-income countries, with over 20 million new cancer cases expected annually as early as $2025 .{ }^{[1]}$ As per the data by Globocan 2012, three most common cancers in India are those of the breast, uterine cervix and oral cavity and together account for approximately $34 \%$ of all the cancers. ${ }^{[2]}$ Breast cancer has emerged as one of the leading causes of cancer among women (14.3\%) in India, with 144,937 new cases and 70,218 deaths reported. ${ }^{[2]}$ Cervical cancer is the second most common cancer in women (12.1\%). Around 1.23 lakh new women are diagnosed with cervical cancer and 67,500 of these women die of the disease each year in India. ${ }^{[2]}$ Oral cancer accounts for around $7.2 \%$ of all cancers in India with 77,003 new cases and 52,067 deaths reported. ${ }^{[2]}$

In 2010, the National Programme for the Prevention and Control of Cancer, Diabetes, Cardiovascular Diseases and Stroke (NPCDCS) was initiated in 100 districts across 21 States in India. State noncommunicable Disease (NCD) cells have been established in all 36 States/Union Territories, and District NCD Cells have been established in 390 districts till March 2017. ${ }^{[3]}$ Screening for common cancers will be implemented through the NPCDCS program in the state government facilities in phased manner. In India, operational guidelines for prevention, screening, and control of common NCDs which also includes common cancers of oral cavity, breast, and cervix have been developed by the National Health Mission since 2016. As per the guidelines screening for common cancers should be carried out as a part of comprehensive primary healthcare (PHC) and can be carried out at PHC level and even at selected subcenters. ${ }^{[3]}$

\begin{tabular}{|c|}
\hline Access this article online \\
\hline Quick Response Code: \\
\\
\\
Website: www.sajc.org \\
\hline DOI: 10.4103 /sajc.sajc_290_18 \\
\hline
\end{tabular}

Departments of Clinical Research, ${ }^{2}$ Biostatistics and ${ }^{4}$ Operational Research, ICMR - National Institute for Research in Reproductive Health, ${ }^{3}$ Department of Preventive Oncology, Tata Memorial Hospital, Mumbai, 'Department of Health Research, Model Rural Health Research Unit Dahanu, Sub District Hospital, Dahanu, Maharashtra, India

Dr.Anushree D. Patil and Dr. Neha Salvi have equal contributions as first author

Correspondence to: Dr. Beena Nitin Joshi,

E-mail:bjoshithane@gmail.com
Palghar is a newly-formed district in Maharashtra, India and has predominant tribal population. Our Institute is designated as a site for Model Rural Health Research Unit of the Department of Health Research to address the local health needs of the population through training and research. Hence, an assessment of training needs and capacity building activity was undertaken as part of larger intervention study to address the unmet need of cancer screening program in the region. To understand the willingness, knowledge, barriers, and facilitating factors, we assessed the perspectives of the Medical Officers of Palghar district of Maharashtra regarding implementation of screening for cancers of breast, uterine cervix, and oral cavity in PHC system of tribal block of Maharashtra.

\section{Materials and Methods}

A continuous medical education (CME) program on "Prevention and early detection of common cancers" was held at Dahanu for all Medical Officers of Palghar District in March 2017. It was also attended by some private practitioners in Palghar district. The CME was conducted by us (ICMR-NIRRH) along with eminent experts from the Department of Preventive Oncology at Tata Memorial Hospital, Mumbai. The healthcare providers were updated about the prevalence of common cancers, their risk factors, screening methods, and human papilloma virus (HPV) vaccination. A self-administered questionnaire was used to assess the knowledge, attitude, and practices regarding cancers of breast, uterine cervix, and oral cavity. The survey was carried out both prior to the commencement and on completion of the CME.

Out of a total 76 participants, 63 participants filled both the pre- and post-test questionnaire. A total of 32 questions were included in the study of which 18 questions were about knowledge and

This is an open access journal, and articles are distributed under the terms of the Creative Commons Attribution-NonCommercial-ShareAlike 4.0 License, which allows others to remix, tweak, and build upon the work non-commercially, as long as appropriate credit is given and the new creations are licensed under the identical terms.

For reprints contact: reprints@medknow.com

How to cite this article: Patil AD, Salvi NR, Shahina B, Pimple AS, Mishra AG, Chauhan LS, et al. Perspectives of primary healthcare providers on implementing cancer screening services in tribal block of Maharashtra, India. South Asian J Cancer 2019;8: 145-9. 
awareness about the subject. Information about the demographics and professional status of the participants was also included. It also had true-false and multiple-choice questions assessing knowledge, attitudes, individual practices or experience related to cancers of breast, uterine cervix, and oral cavity. Questions were also asked pertaining to HPV vaccination, dosages, availability, and willingness to administer. Training needs of healthcare providers, willingness to screen and the opinion of providers for the suitable method and strategies for effective implementation of screening was also assessed. The responses before and after the training session were compared using McNemar test and $P<0.05$ considered as statistically significant. The data were entered and analysis was performed using the statistical package SPSS (version 19.0; IBM Corporation, Armonk, NY, USA).

\section{Results}

The mean age of the respondents was $41.9( \pm 10.1)$ years. Majority (59\%) of the healthcare providers were young in the age group of 26-45 years and males (71\%). The doctors in this area were from different streams of medicine such as allopathy, homeopathy, Ayurveda but all were catering to PHC. About $76 \%$ were practicing in government hospitals, whereas $22 \%$ were private practitioners. Most of the practitioners had 10-20 years of experience of practicing in PHC.

\section{Knowledge about common cancers}

Most of the providers $(98.4 \%)$ correctly recognized that the purpose of screening for cancer was to detect them early. Majority $(81 \%)$ were aware that precancerous lesions of the cervix could be asymptomatic, but only $21 \%$ knew that the period from precancerous changes to cervical cancer could be as long as 10-20 years. Sixty percent were aware that visual inspection with acetic acid (VIA) is used as a method to screen for cervical cancer. Only 16\% could correctly identify all four symptoms of cervical cancer and only $18 \%$ all the four warning signs of oral cancer. The awareness about the Government of India's program for screening of common cancers and NCD's was poor (46\%) which was improved after the CME [Table 1].

\section{Knowledge about human papillomavirus and human} papilloma virus vaccination

Majority (87\%) knew that HPV was the causative agent for cervical cancer, but only $55 \%$ were aware that it is transmitted sexually. In posttest, there was improved awareness about the availability of HPV test as a screening modality. Sixty-five percent $(65 \%)$ were aware that HPV vaccine is used to prevent cervical cancer, but only $37 \%$ knew that three doses of the vaccine were required. Less than half of the practitioners were aware that the right time to give vaccine was in adolescence before the onset of sexual activity. The knowledge about the common cancers was found to be significantly improved in the post-test survey undertaken after completion of the CME [Table 2]. In very few areas, there was slight decline in the posttest which was not significant and perhaps, this was because the providers completed the pretest with more attention than the posttest.

\section{Knowledge about risk factors for cervical, breast, and oral cancer}

Knowledge of the major risk factors was considerably poor among the respondents with only $4.7 \%$ identifying all risk factors for cervical cancer, $1.6 \%$ identifying all risk factors for breast cancer, and $16 \%$ identifying all risk factors for oral cancer. Details are summarized in Table 3.

\section{Attitudes}

Most of the doctors (86\%) felt that screening for common cancers should be an essential part of PHC. Majority (75\%) of the respondents felt it was feasible to implement screening for common cancers (cervical, breast, and oral) at PHC level. About 78\% felt it was feasible to perform VIA at PHC level for the screening of cervical cancer. Almost all the providers (98.4\%) felt that the frontline workers like auxiliary nurse midwives (ANMs) could be trained to perform VIA and to implement screening. Most feasible approach to cancer screening as per respondents was opportunistic screening, i.e., when a patient visits health facility (59\%), followed by camp approach (56\%), fixed days for screening at health facility (43\%) and population-based screening by going to the community (40\%) [Figure 1]. Most of the providers (96.8\%) were willing to provide HPV vaccination to prevent cervical cancer.

\section{Perceived barriers}

Most common perceived barriers to implementing cancer screening were inadequate training $(75 \%)$, lack of laboratory facility $(75 \%)$ followed by lack of equipment (67\%). Only $44 \%$ felt patient/women acceptability and lack to follow up as barriers to implementing the screening program. Figure 2 represents some of the perceived barriers.

\section{Screening methods practiced by participants}

Facilities for Pap smear were not available in the government set up but were occasionally done in collaboration with private laboratories when required. Most respondents used more than one method for screening for breast cancer. About $63.5 \%$ of the respondents worked on creating awareness and teaching self-breast examination. Clinical breast examination was used as a screening method by approximately $50 \%$ of the respondents whereas only $11 \%$ used ultrasonography of breast as a screening tool. Facilities such as mammography and sonography of breast were not available in the government set up. Oral cancer screening was not performed.

\section{Training needs and willingness of healthcare providers}

\section{for cancer screening}

Only a small number of respondents had received training in screening for cervical cancer $(16 \%)$, breast cancer $(17.5 \%)$ and oral cancer $(13 \%)$. Majority $(80 \%)$ were willing to receive training for the screening of cervical, breast, and oral cancer.

Table 1: Knowledge about common cancers during pre and post CME

\begin{tabular}{|c|c|c|c|}
\hline Knowledge areas & Pretest $(n=63) n(\%)$ & Posttest $(n=63) n(\%)$ & $P$ \\
\hline $\begin{array}{l}\text { Purpose of screening for cervical, breast and oral cancer is to detect them } \\
\text { early is understood }\end{array}$ & $62(98.4)$ & $59(93.7)$ & 0.09 \\
\hline Precancerous lesions of cervix can be asymptomatic & $51(81)$ & $57(90.5)$ & 0.45 \\
\hline $\begin{array}{l}\text { Period of progression from precancerous cells to cancer in cervical cancer } \\
\text { can take } 10-20 \text { years }\end{array}$ & $13(20.6)$ & $29(46)$ & 0.039 \\
\hline Visual inspection with acetic acid is used screening for cervical cancer & $38(60.3)$ & $52(82.5)$ & 0.0001 \\
\hline Awareness about government programme on screening of common cancers & $29(46)$ & $51(81)$ & 0.0001 \\
\hline
\end{tabular}


Table 2: Knowledge about HPV and HPV vaccine during pre and post CME

\begin{tabular}{|c|c|c|c|}
\hline Knowledge areas & Pretest $(n=63) n(\%)$ & Posttest $(n=63) n(\%)$ & $P$ \\
\hline Cervical cancer is caused - Human Papilloma Virus & $55(87.3)$ & $60(95.2)$ & 0.10 \\
\hline Virus associated with cervical cancer is transmitted by sexual route & $35(55.6)$ & $38(60.3)$ & 0.42 \\
\hline Have you heard of HPV testing for cervical cancer screening- yes & $41(65.1)$ & $59(93.7)$ & 0.0007 \\
\hline Vaccine for prevention of cervical cancer- HPV vaccine & $41(65.1)$ & $60(95.2)$ & 0.0001 \\
\hline How many doses of HPV vaccine are required- 3 doses & $23(36.5)$ & $33(52.4)$ & 0.10 \\
\hline $\begin{array}{l}\text { Age when vaccine is given for prevention of cervical } \\
\text { cancer- before onset of sexual activity in adolescents }\end{array}$ & $28(44.4)$ & $38(60.3)$ & 0.007 \\
\hline
\end{tabular}

Table 3: Knowledge about risk factors for cervical, breast and oral cancers

\begin{tabular}{|c|c|c|c|}
\hline & Pretest $(n=63) n(\%)$ & Posttest $(n=63) n(\%)$ & $P$ \\
\hline \multicolumn{4}{|c|}{ Risk factors for cervical cancer - multiple options } \\
\hline Infection with HIV & $23(36.5)$ & $18(28.6)$ & 0.23 \\
\hline Infection with HPV & $46(73)$ & $60(95.2)$ & 0.001 \\
\hline Having multiple sexual partners & $41(65.1)$ & $44(69.8)$ & 0.81 \\
\hline Smoking cigarettes & $17(25.4)$ & $16(25.4)$ & 0.82 \\
\hline Early age of sexual intercourse & $30(47.6)$ & $50(79.4)$ & 0.0001 \\
\hline \multicolumn{4}{|c|}{ Risk factors for breast cancer - multiple options } \\
\hline Increasing age & $25(39.7)$ & $34(54)$ & 0.03 \\
\hline Positive family history & $43(68.3)$ & $58(92.1)$ & 0.0004 \\
\hline High fat diet & $20(31.7)$ & $38(60.3)$ & 0.0006 \\
\hline Race/Ethnicity & $16(25.4)$ & $22(34.9)$ & 0.09 \\
\hline First pregnancy at early age & $30(47.6)$ & $46(73)$ & 0.0001 \\
\hline Early age of onset of menarche & $13(20.6)$ & $39(61.9)$ & 0.0001 \\
\hline Late menopause & $18(28.6)$ & $40(63.5)$ & 0.0003 \\
\hline \multicolumn{4}{|c|}{ Risk factors for oral cancer - multiple options } \\
\hline Tobacco use & $60(95.2)$ & $60(95.2)$ & 0.95 \\
\hline Alcohol consumption & $14(22.2)$ & $14(22.2)$ & 0.91 \\
\hline HPV virus & $17(27)$ & $16(25.4)$ & 0.82 \\
\hline Pan/Supari & $45(71.4)$ & $41(65.4)$ & 0.24 \\
\hline
\end{tabular}

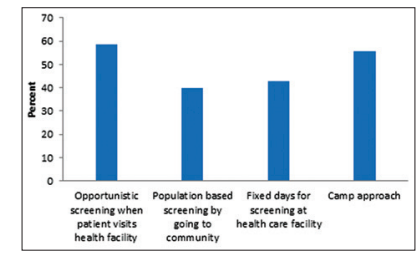

Figure 1: Healthcare provider's perspective about feasible approach to cancer screening in primary health care

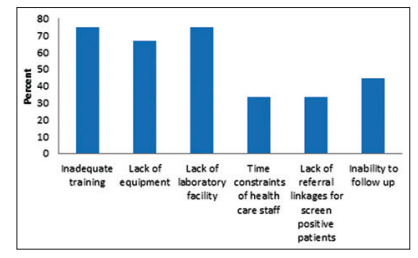

Figure 2: Perceived barriers by healthcare providers for implementing cancer screening at primary health care
About $78 \%$ of the respondents felt confident that they would be able to screen for cervical, breast, and oral cancer if they received appropriate training.

\section{Discussion}

Cervical, breast, and oral cancer are amenable to early detection and treatment thereby reducing cancer-related mortality and morbidity. Cancer of the oral cavity and cervix are amenable to secondary prevention through screening methods and can be detected and treated at precancerous stages. ${ }^{[3]}$ The vast majority of cervical cancer-related deaths are among women that have never been screened. There is increased emphasis by the government on early detection of common cancers and its implementation through the NPCDCS program in rural and underserved areas. Since most of our respondents were working in government healthcare facilities, the purpose of the study was to assess the perspectives of the medical officers of Palghar district of Maharashtra regarding implementation of screening for cancers of breast, uterine cervix, and oral cavity in PHC system and to understand the barriers as well as facilitating factors.

South Asian Journal of Cancer • Volume 8 •Issue 3 • July-September 2019
In India, Pap smear-based screening programs at $\mathrm{PHC}$ need infrastructure, resources, and expertise. Furthermore, it takes almost 15 days to know the Pap smear result. Hence, VIA has been suggested an alternative strategy, which is scientifically correct, ethical, and feasible. ${ }^{[4]}$ The operational framework on the management of common cancers also recommends VIA as a screening method for cervical cancer for all women over 30 years of age. ${ }^{[3]}$ The country-specific reduction in the lifetime risk of invasive cervical cancer with a single screening at the age of 35 years ranged from $25 \%$ to $31 \%$ with VIA at one-visit and two-visit, respectively. ${ }^{[5]}$ The total discounted costs for a single lifetime screening strategy (one-visit visual inspection) was lowest in India (\$24.20). ${ }^{[5]}$

It was also observed that most of the health care providers were males and women may not feel comfortable. Hence, ANMs may be a good choice to do the screening of common cancers. In our results, 98\% healthcare providers felt that ANMs could be trained to perform cancer screening. The guidelines for Cervical Cancer Screening Program also suggest trained female health worker can perform VIA. Operation framework on common cancers mentions ANM's will be trained to screen for cervical, breast, and oral cancer. A study by Shastri et al. concluded that VIA screening by primary health workers statistically and significantly reduced cervical cancer mortality. ${ }^{[6]}$ Hence, there is a need to focus on the simple basic training of the ANMs as they are in direct contact with the women population.

Clinical breast examination performed by trained female healthcare workers is a low-cost approach for screening of 
breast cancer in low- to medium-resource countries. In a developing country like India, late stage at diagnosis, the average size of the tumor and the socioeconomic realities make CBE a viable modality for initial, baseline screening for breast cancer. ${ }^{[3]}$ Higher yield is obtained for breast cancer when women over 40 years are screened, but the screening age is kept at 30 years for programmatic and operational purposes. ${ }^{[3]}$ The oral cavity is easily accessible and oral cancers are preceded by disorders or lesions which can be detected early during routine check-up/screening by doctors/dentist/health workers or by self-examination. A study by Sankaranarayanan et al. demonstrates greater benefit in screening those for oral cancer who use tobacco in any form or alcohol or both. ${ }^{[7]}$ Healthcare providers can prioritize screening in group with this behavior and may also screen younger people with this behavior.

As per operational framework initially, districts performing well under the NPCDCS program will be initially selected. Once the district is selected the state will decide the PHC and the sub-centers that will be prepared to initiate the screening for common cancers.

Studies done among other developing countries like Ethiopia also show similar findings and have reported lack of training (52\%) and resources $(53 \%)$ as barriers to screening further emphasizing the need for training healthcare providers in low-tech, low-cost screening methods. ${ }^{[8]}$ In Nigeria, healthcare providers are encouraged to improve on opportunistic screening and to have a national screening policy for cancer screening. ${ }^{[9]}$ Reasons for low practice of cervical cancer screening among healthcare workers needs to be investigated. ${ }^{[10,11]}$ Introduction of easier-to-perform and less costly screening modalities like VIA/visual inspection with Lugol's Iodine may improve uptake of screening. ${ }^{[12]}$

There are a few studies from India mostly involving staff nurses. Knowledge of cancer cervix, screening, and practice of Pap smear was low among Sikkimese nursing staff in India. Hence, there is an urgent need for re-orientation course for working nurses and integration of cervical cancer prevention issues in the nurses' existing curriculum in India and other developing countries. ${ }^{[13]}$ A study conducted in Chennai reiterated that misconceptions regarding screening need to be urgently addressed among healthcare providers. ${ }^{[14]}$ In Uttarakhand female nursing staff had the average knowledge and positive attitude toward cervical cancer screening. ${ }^{[15]}$ The present study also showed the positive attitudes of health care providers toward implementation of common cancer screening services at PHC level.

\section{Conclusion}

The training/CME showed a significant improvement in the knowledge of cancer screening of healthcare providers. There is a strong willingness of healthcare providers to get trained in cancer screening and also to implement it even in tribal areas which are underserved. However to sustain their enthusiasm and build skills, continuous and focused efforts will be required.

\section{Recommendations}

For an effective screening program capacity building of healthcare providers is very essential. The staff involved in screening such as health workers, ANMs and medical officers need to be trained in cancer screening. Hence, training activities and referral linkages need to be strengthened during the operationalization of the guidelines for cancer screening in India. Only training is not sufficient. The primary level care providers need ongoing support while actually implementing the program and also there needs to be feedback mechanism from the tertiary care that could improve the involvement of the providers in patient management. There is a need to educate about HPV vaccination and its implementation in PHC. This may go a long way in reducing the burden of cervical, breast, and oral cancers in developing countries.

\section{Acknowledgment}

We would like to acknowledge the support of Palghar District health officials Dr. Arun Yadav, Dr. Abhijit Chavhan, Dr. Sagar Patil in conduct of the CME and all the participating Medical Officers. We also acknowledge the encouragement and financial support provided by ICMR-NIRRH Director, Dr. Smita Mahale. We also acknowledge the technical help provided by our staff Sister Ruhi Pednekar, Sister Rachana Dalvi, Mrs Pratibha Kokate, Mr Sanjay and Mrs Anamika Akula.

\section{Financial support and sponsorship}

This study was supported by ICMR-National Institute for Research in Reproductive Health.

\section{Conflicts of interest}

There are no conflicts of interest.

\section{References}

1. Bray F. Transitions in human development and the global cancer burden. In: Wild CP, Stewart B, editors. World Cancer Report 2014. Lyon: International Agency for Research on Cancer; 2014.

2. Ferlay J, Soerjomataram I, Ervik M, Dikshit R, Eser S, Mathers C, et al. GLOBOCAN 2012 v1.0, Cancer Incidence and Mortality Worldwide: IARC Cancer Base No. 11. Lyon, France: International Agency for Research on Cancer; 2013.

3. National Health Mission. Operational Guidelines for Prevention, Screening and Control of Common non- Communicable Diseases. India: Ministry of Health and Family Welfare, Government of India; 2016.

4. Guidelines for Cervical Cancer Screening Programme. Recommendations of the Expert Group Meeting, 18-19 November 2006; Government of India-World Health Organization Collaborative Programme (2004-2005). Department of Cytology \& Gynecological Pathology, Postgraduate Institute of Medical Education and Research, Chandigarh, India; June, 2006.

5. Goldie SJ, Gaffikin L, Goldhaber-Fiebert JD, Gordillo-Tobar A, Levin C, Mahé $\mathrm{C}$, et al. Cost-effectiveness of cervical-cancer screening in five developing countries. N Engl J Med 2005;353:2158-68.

6. Shastri SS, Mittra I, Mishra GA, Gupta S, Dikshit R, Singh S, et al. Effect of VIA screening by primary health workers: Randomized controlled study in Mumbai, India. J Natl Cancer Inst 2014;106:dju009.

7. Sankaranarayanan R, Ramadas K, Thomas G, Muwonge R, Thara S, Mathew B, et al. Effect of screening on oral cancer mortality in Kerala, India: A cluster-randomised controlled trial. Lancet 2005;365: 1927-33.

8. Kress CM, Sharling L, Owen-Smith AA, Desalegn D, Blumberg HM, Goedken J, et al. Knowledge, attitudes, and practices regarding cervical cancer and screening among Ethiopian health care workers. Int J Womens Health 2015;7:765-72.

9. Nwobodo El, Malami SA. Knowledge and practice of cervical screening among female health workers in Sokoto, North Western Nigeria. Niger Postgrad Med J 2005; 12:255-7.

10. Dulla D, Daka D, Wakgari N. Knowledge about cervical cancer screening and its practice among female health care workers in Southern Ethiopia: A cross-sectional study. Int J Womens Health 2017;9:365-72.

11. Amal A, Mohamed S, Hisham E, Noora A, Zeliakha A, Muna T, et al. Knowledge, attitudes and practices regarding cervical cancer screening among Female health care workers in primary healthcare in Qatar. Mid East J Fam Med 2016; 14:4-15.

12. Eze GU, Obiebi IP, Umuago IJ. Perspectives of cervical cancer and South Asian Journal of Cancer Volume 8 • Issue $3 \bullet$ July-September 2019 
screening practices among staff of a teaching hospital in South-South Nigeria. J Cancer Res Pract 2018;5:67-73.

13. Rahman H, Kar S. Knowledge, attitudes and practice toward cervical cancer screening among sikkimese nursing staff in India. Indian J Med Paediatr Oncol 2015;36:105-10.

14. Anantharaman VV, Sudharshini S, Chitra A. A cross-sectional study on knowledge, attitude, and practice on cervical cancer and screening among female health care providers of Chennai corporation. J Acad Med Sci 2012;2:124-8

15. Pegu B, Dhiman N, Chaturvedi J, Sharma SK. Nurse's knowledge and attitude regarding cervial cancer screening at a tertiary care hospital. Int J Reprod Contracept Obstet Gynecol 2017;6:907-10. 